\title{
The Use of Bone Age in Clinical Practice - Part 2
}

\author{
David D. Martin ${ }^{a} \quad J a n$ M. Wit ${ }^{d} \quad$ Ze'ev Hochberg $^{f}$ Rick R. van Rijn ${ }^{\mathrm{e}}$ Oliver Fricke ${ }^{b}$ \\ George Wertherg Noël Cameron $^{\mathrm{h}}$ Thomas Hertel ${ }^{j}$ Stefan A. Wudy ${ }^{\mathrm{c}}$ \\ Gary Butler $^{i}$ Hans Henrik Thodbergk ${ }^{k}$ Gerhard Binder ${ }^{a} \quad$ Michael B. Ranke $^{a}$ \\ a Pediatric Endocrinology and Diabetology, University Children's Hospital, Tübingen, ${ }^{b}$ Children's Hospital, \\ University of Cologne, Cologne, and 'Paediatric Endocrinology and Diabetology, Justus Liebig University, Giessen, \\ Germany; ${ }^{d}$ Department of Pediatrics, Leiden University Medical Center, Leiden, and 'Department of Radiology, \\ Emma Children's Hospital/Academic Medical Center Amsterdam, Amsterdam, The Netherlands; ${ }^{\mathrm{f}}$ Meyer Children's \\ Hospital, Rambam Medical Center, Haifa, Israel; ${ }^{9}$ Department of Endocrinology, Royal Children's Hospital \\ Parkville, Parkville, Vic., Australia; ${ }^{\mathrm{h} C e n t r e ~ f o r ~ G l o b a l ~ H e a l t h ~ a n d ~ H u m a n ~ D e v e l o p m e n t, ~ L o u g h b o r o u g h ~ U n i v e r s i t y, ~}$ \\ Loughborough, and 'Institute of Child Health, University College London and University College London Hospital, \\ London, UK; ${ }^{j}$ H.C. Andersen Children's Hospital, Odense University Hospital, Odense, and kVisiana, Holte, Denmark
}

\section{Key Words}

Skeletal maturity $\cdot$ Bone age $\cdot$ Tall stature $\cdot$

Precocious puberty $\cdot$ Congenital adrenal hyperplasia $\cdot$

Bone mineral density

\begin{abstract}
If height-limiting treatment is being considered for a child with tall stature, skeletal maturity is invaluable in the selection of appropriate patients for treatment, determining appropriate age of treatment commencement, monitoring progress of treatment, and determining the expected treatment effect on adult height. In precocious puberty, bone maturation can be usefully assessed at initial diagnosis and start of treatment and at regular intervals thereafter during treatment monitoring. Together with height, bone maturation is an essential parameter for long-term treatment monitoring in congenital adrenal hyperplasia. Bone age (BA) determination in children with skeletal dysplasia is only feasible in a few disorders and estimations should be treated with caution. Radiographs of the left hand and wrist are, however, essential in the diagnosis of many skeletal disorders. Bone mineralization and measures of bone lengths, width, thick-
\end{abstract}

ness and cortical thickness should always be evaluated in relation to a child's height and BA, especially around puberty. The use of skeletal maturity, assessed on a radiograph alone to estimate chronological age for immigration authorities or criminal courts is not recommended.

Copyright $\odot 2011$ S. Karger AG, Basel

\section{Introduction}

Part 1 of this review dealt with the following themes: the negligible radiation dose involved in the hand-wrist radiograph required to assess bone maturation [also called skeletal maturity, or bone age (BA)], the various methods of assessment currently employed in clinical routine, and the use of such assessment in children with short stature of various etiologies. Part 2 deals with the use of bone maturation films in children with tall stature, precocious puberty (PP), congenital adrenal hyperplasia (CAH), skeletal dysplasias, and unknown chronological age, and with the possibility of using BA to evaluate bone mineral density and a possible secular trend.

Dr. David D. Martin

Pediatric Endocrinology and Diabetology, University Children's Hospital Hoppe-Seyler Strasse 1

DE-72076 Tübingen (Germany)

Tel.+49707 1298 3795, E-Mail david.martin@med.uni-tuebingen.de 


\section{Tall Stature}

In some countries, children with extreme tall stature have the (controversially discussed) option of treatment with sex steroids to accelerate epiphyseal fusion or of growth plate drilling to limit adult height. Bone maturation estimates as a means to assess residual growth potential is invaluable in the clinical and research situation regarding tall stature, for:

(1) selection of appropriate patients for treatment,

(2) determining appropriate time for treatment commencement,

(3) monitoring progress of treatment, and

(4) determination of treatment effect on adult height.

The relationship between bone maturation and height must be considered: tall children will be expected to have slightly advanced BA, in accordance with their 'advancement' in height.

In a comparison of adult height prediction methods used on children with tall stature, Joss et al. [1] concluded that there is no best or most accurate method for predicting adult height in tall children: both the Tanner-Whitehouse mark II and the Bayley-Pinneau method tend to overestimate adult height at various BAs, especially the Bayley-Pinneau method up to a bone maturation of 12 'years' in boys and 14 'years' in girls. Binder et al. [2] found an overprediction of the Bayley-Pinneau method of only $0.14 \mathrm{~cm}( \pm 3.10)$ in girls and of $1.86 \mathrm{~cm}( \pm 4.37)$ in boys.

Early high-dose treatment with estrogen (for girls) or testosterone (for boys) was found to reduce adult height by between 2 and $10 \mathrm{~cm}$ in the mostly small follow-up studies between the 1950s and the 1990s, which were mainly based on bone maturation-derived height predictions.

In a large retrospective Dutch study of girls who all had a predicted adult height above $181 \mathrm{~cm}$, the total mean (SEM) reduction of adult height was $5.9(0.2) 5.3(0.1)$, and $4.4(0.2) \mathrm{cm}$ when treated with $0.5,0.25$, and $0.1 \mathrm{mg}$ ethinyl estradiol per day, respectively. Group $1(\mathrm{n}=263)$ was treated for $2.02(0.03)$ years, group $2(\mathrm{n}=178)$ for 1.85 $(0.04)$ years, and $3(n=98)$ for $1.63(0.05)$ years. When expressed in relation to the treatment period, the reduction of adult height was $3.0(0.1), 3.1(0.1)$, and $2.9(0.2) \mathrm{cm} /$ year of treatment, respectively. All the girls were treated with ethinyl estradiol as a daily single dose, while progestogen was given daily the first 10 days of every month. Hence $0.1 \mathrm{mg}$ ethinyl estradiol daily for about 20 months was sufficient to reduce adult height. Here the recommendation was made to start treatment at a bone maturation of about 12 'years' [3] - although with very tall girls one should begin earlier to achieve a worthwhile effect.
In an Australian study, adult height, compared to Bayley-Pinneau predictions derived from the Greulich-Pyle Atlas, was underestimated by a mean of $1.86( \pm 0.18) \mathrm{cm}$ in the untreated group while the treated group ended up $2.13( \pm 0.2) \mathrm{cm}$ below their pretreatment prediction. Multivariate regression showed that pretreatment skeletal maturity strongly predicted outcome. To remove bias in the height prediction model, a matched-pair analysis based on adult height prediction allowed 108 treated and untreated pairs to be matched. A treatment effect of 2.4 $\mathrm{cm}(95 \% \mathrm{CI}-3.2$ to 1.8$)$ reduction in adult height was determined, and pretreatment BA again strongly predicted outcome, with a $6-\mathrm{cm}$ reduction if treatment in girls commences at BA 10 , and a $1-\mathrm{cm}$ reduction for each later BA 'year' of commencement [4].

In a retrospective study from Tübingen comprising a daily oral dose of $7.5 \mathrm{mg}$ conjugated estrogens (plus $5 \mathrm{mg}$ dydrogesterone for 10 days a month), the mean corrected effect of height-reducing therapy in girls was $3.6 \mathrm{~cm}$ (range: 11.9 to $-3.3 \mathrm{~cm}$ ) compared with untreated girls. Treatment was well tolerated [2]. In boys, using $500 \mathrm{mg}$ testosterone enanthate intramuscularly every 2 weeks [2], the mean corrected effect of height-reducing therapy was $4.4 \mathrm{~cm}$ (range: 14.2 to $-5.2 \mathrm{~cm}$ ). Therapy was significantly more effective when started at an earlier chronological age and BA, with only $1 \mathrm{~cm}$ benefit when starting at a BA of 13.5 in girls and 14.5 in boys - in line with Drop and colleagues [5] who actually found a negative effect over predicted adult height in boys who began treatment with a BA of more than 14 'years'. There is as yet no consensus as to when treatment should be stopped: while Brämswig et al. [6] advocated and still practice [J. Brämswig, pers. commun.] a treatment duration of 6 months only, others have recommended not to discontinue therapy before complete closure of the epiphyses of the hand has occurred to avoid considerable posttreatment growth [5], and still others base stopping treatment on height velocity only. Recently, reports from Australia [7] and the Netherlands [8] indicated that estrogen treatment in adolescence may be associated with an increased likelihood of fertility problems, which further discourages the use of estrogens for this indication. In men, androgen treatment of tall stature does not seem to affect fatherhood or semen quality but serum testosterone levels are reduced [9].

In conclusion, the need for growth attenuation treatment of adolescents with tall stature is limited and longterm adverse effects have been reported so that treatment is not recommended in most cases. However, pediatric endocrinologists are regularly faced with patients 
wanting a reduction of adult height and may still consider this treatment or alternative treatments such as surgical epiphysiodesis in extreme cases. A BA assessment is of invaluable help in assisting the decision-making process.

\section{Pubertal Disorders}

The fundamental role of sex steroids in bone maturation is obvious from the marked delay in skeletal maturity of children with delayed puberty and its advancement in children with PP. The effect of sex steroids overrides all other effects, so that bone maturation loses its relationship to a child's calendar age during adolescence and correlates instead with the pubertal stages. Thus, the morphologic difference between a female BA of 12 and 13 'years' is far greater than it is between a BA of 6 and 7 'years'. Since estrogen is the agent involved in maturation and closure of the epiphyseal plate in both genders [10], aromatase inhibitors can be used to slow bone maturation. This has been shown to be of value in GnRH-independent forms of PP such as testotoxicosis (familial male limited PP) [11] or Peutz-Jeghers syndrome [12]. Randomized placebo-controlled studies using aromatase inhibitors in boys with pubertal delay [13], idiopathic short stature $[14,15]$ or growth hormone deficiency [16] have also shown an increase in predicted adult height, but its use in this and all other indications in pediatrics is off label and considered experimental. Further studies are needed to establish whether the adult height attained by some children with short stature can be improved by aromatase inhibitors and what role BA assessment can play in treatment decisions and monitoring in this context [17-20].

\section{Precocious Puberty}

PP is most commonly defined as start of puberty before the age of 9 years in boys and 8 years in girls. It is usually subcategorized into central (gonadotropindependent) and peripheral (gonadotropin-independent, pseudo-) PP. While the early onset of breast development in girls and genital development in boys is the essential criterion of PP, there are several other clinical features, such as increased growth velocity, increased skeletal maturation, and uterine growth. The diagnosis of $\mathrm{PP}$ and its subcategories is based on physical examination, analysis of growth, assessment of bone maturation, ultrasound examination of the uterus and gonads, and hormone tests.

Since in PP the premature exposure to sex hormones accelerates bone maturation, a skeletal maturity assessment is part of the initial workup of every child with early appearance of pubertal signs. The definition of rapidly progressing $\mathrm{PP}$ encompasses rapid bone maturation ( $>2$ SD for age), while in pubertal variants (precocious adrenarche, or premature thelarche) it is usually only 1-2 SD above chronological age [21]. Yet, when central PP is diagnosed early, there may be only a slight advance.

In some children, the progression of central PP may not be sustained or very slow, with bone growth and maturation rates close to normal and with the preservation of predicted adult height. Hence, repeated bone maturation monitoring instead of immediate initiation of treatment is occasionally required and in some cases will serve to reassure the physician that treatment is not necessary. In girls older than 6 years of age at diagnosis of central $\mathrm{PP}$, posttreatment acceleration of BA and early epiphyseal fusion compromise adult height potential [22].

Appropriate timing for discontinuation of $\mathrm{GnRHa}$ treatment of central PP is also related to bone maturation. It has been demonstrated that residual growth capacity in treated children with central PP is optimal if GnRHa treatment is stopped at a BA of 12-12.5 'years' [23-25]. However, bone maturation needs to be taken in context because a BA of approximately 12 'years' can be observed at different chronological ages and because the height gain after treatment is dependent on the age at which treatment was started: only girls who are diagnosed with central PP and treated before the chronological age of 6 years and stopped treatment at a BA of 12 'years' reached the height predicted at the cessation of treatment and achieved target height [22]. In practice, $\mathrm{GnRH}$ agonist treatment is often discontinued individually in concordance with the pubertal development of the patient's peers and the family history - with a little delay if one is trying to achieve maximum adult height.

Sex steroids affect the short bones much more than the long bones or carpal bones [26]. Thus, Vejvoda and Grant [27] found that the short bones advanced faster than the carpal bones in 9 patients with PP. More recent results using the same Tübingen cohort as in Martin et al. [28] support their statement and additionally show that carpals hardly respond to $\mathrm{GnRH}$ agonist treatment and thus catch up with the short bones (which respond to treatment by showing no or very little maturation) during treatment. This implies that the carpals are less useful than the short bones for diagnosis or monitoring the 
treatment of puberty disorders. Estrogen appears to have a stronger and faster influence on growth plates than on the appositional growth of the carpal bones [28].

Slowing of bone maturation contributes to improving adult height in central PP. Since the outer signs of puberty, such as breast development or enlarged testes and penis, do not completely regress, bone maturation is an important monitoring instrument. Rapid bone maturation during treatment requires prompt reassessment of compliance [29].

The most widely used methods of adult height prediction are those of Bayley-Pinneau and Tanner-Whitehouse, which have yet to be validated in children with PP. A systematic overestimation of adult height between 4 and $13 \mathrm{~cm}$ was recorded in both untreated and treated girls [30,31]. In treated girls, the predictions of increased height given throughout the treatment period due to the deceleration of bone maturation proved to have been overly optimistic [22]. BA is thus a useful diagnostic and monitoring tool for children with $\mathrm{PP}$, provided that its limitations in clinical practice are recognized.

\section{Congenital Adrenal Hyperplasia}

$\mathrm{CAH}$ is an autosomal recessive metabolic disease. In most forms, excess formation of androgens leads to virilization of varying degree and (pseudo) PP. In other, rare, forms of $\mathrm{CAH}$, formation of sex steroids is reduced or not possible; in these entities, bone maturation is typically delayed [32]. The role of adrenal androgens - via local aromatization into estrogens - is well established for its rapid maturational impact on bone development in children with CAH. The effect is greatest on the short bones (fingers and metacarpals), intermediate on the cuboid bones (carpals) and minimal on the long bones (radius and ulna) of the hand [26].

If left untreated, the overproduction of androgens in virilizing $\mathrm{CAH}$ usually leads to accelerated growth and bone maturation. Typically, the pattern of skeletal maturation shows relative advancement of phalanges over carpals $[26,33]$. In untreated $\mathrm{CAH}$, the growth pattern in early and mid childhood reveals tall stature but - due to premature closure of epiphyses - later results in short adult stature in most patients [34-38]. However, it is interesting to note that bone maturation in untreated virilizing CAH does not occur during the first 2 years of life $[26,39,40]$.

Attainment of normal adult stature is one of the primary goals in the treatment of CAH. This primarily con- sists of providing the patient with enough glucocorticoids and, if necessary, mineralocorticoids to suppress ACTHmediated excess androgen production - monitored by regular measurement of diagnostically important key hormones or metabolites, height, weight and bone maturation. Finding the correct dosage poses a special challenge because even slight overdoses of glucocorticoids will curb growth and bone maturation [36, 38, 41-43]. A metaanalysis of 18 studies carried out from 1977 to 1997 found a mean adult height following glucocorticoid treatment of -1.37 SDS below the respective population mean [41].

Thus, assessing bone maturation is useful both in the diagnostic evaluation of suspected $\mathrm{CAH}$ as well as in the monitoring of treatment of children with CAH [44]. For optimal control, height and weight should be measured every 3 months and bone maturation at least yearly.

\section{Skeletal Dysplasia}

Skeletal dysplasias are a heterogeneous group of disorders mainly affecting the skeleton; the estimated overall incidence is 1 case in 4,000-5,000 births. Almost all lead to moderate to severe short stature, usually disproportionate. Achondroplasia is one of the more frequent disorders ( 1 in 25,000 births). The mean adult height with this disorder is around $131 \mathrm{~cm}$ for men and $124 \mathrm{~cm}$ for women. BA determination in children with skeletal dysplasia is only possible in a few disorders and estimations should be treated with caution. Radiographs of the left hand are, on the other hand, part of the skeletal survey and essential in the diagnosis of many skeletal disorders. It is of importance to note that the diagnosis of a skeletal dysplasia can be very difficult - and in many cases as yet impossible - and usually requires close collaboration between the pediatrician, clinical geneticist and pediatric radiologist. A full radiologic skeletal survey is indicated in all patients with disproportionate short stature, as recently reviewed [45].

\section{BA and the Evaluation of Bone Mineral Mass and Density}

It is now well known in bone densitometry that $Z$ scores instead of $T$ scores need to be used in children $[46,47]$. The problem of the $\mathrm{Z}$ score lies in the fact that it compares the patient with a group of children with the same chronological age which does not necessarily reflect the height or maturity of the individual. Though reference values for 
bone mineral density against bone maturation are not yet available, in bone densitometry the use of bone maturation makes sense [48]. To avoid errors when interpreting the bone mineral mass or density, muscle mass or force [49], as well as height and BA need to be taken into consideration.

\section{Estimating Chronological Age when the Date of Birth Is Unknown}

Pediatricians are sometimes put in the uncomfortable position of being asked to estimate the chronological age of a child for immigration authorities or the criminal courts. Automated BA reading may contribute to the standardization of BA estimation but will not solve the problem that precisely those children for which such tests are needed have a very mixed (and often disadvantaged) socioeconomic, ethnic, genetic, and nutritional background - all factors which may have an impact on BA [50]. There are as yet no models developed on the basis of these parameters in the relevant populations. Given the lack of evidence and the socioeconomic impact of this (nonmedical) evaluation, providing an age estimate to immigration authorities or the criminal courts has no scientific foundation and should be avoided [51-53].

\section{BA and Secular Trends in Growth and Pubertal Development}

Evidence for a secular trend in the reduction of the age at which various milestones of puberty are reached is very variable from region to region. The age at menarche had consistently fallen over the 20th century, but there is a suggestion of a slowdown in the age decline in more northern Europeans, hence by inference that a minimum age has been reached [54]. More detailed records of pubertal staging shows much variation. The US-wide observations from national studies and individual records by local pediatricians note a fall in the age of onset of puberty, but not such similar reductions in ages at pubertal completion, implying that the pubertal process is becoming prolonged in the current generation [55]. This finding has also been observed in a historic and a contemporary Danish cohort of children followed longitudinally $[56,57]$. An increased size of the current generation was noted but the gain in weight was not sufficient to fully explain the trend. These findings are not evident in less socially advantaged populations such as in Russian Chapaevsk boys [58].
What effect therefore is seen on the rate of BA maturation? Urban Chinese children from Beijing are showing earlier skeletal maturation with a significantly earlier peak in BA acceleration than the TW3 standards and, in comparison with rural Chinese, adult status is achieved 2 years sooner [59]. The pattern of maturation in the Beijing children matches that of those from the Japanese capital Tokyo. A similar trend towards earlier maturity was seen in the Madeira growth study [60]. The maturation of the radius, ulna and short bones proceeded earlier in boys, but both sexes demonstrated a 2-year advance of the age of peak skeletal maturity velocity. Interestingly, this trend was only slightly apparent for the carpal bones. Part of the variations in the extent of the advance in skeletal maturity status may be attributable to the method of BA estimation. In a comparison of two systems, the TW3 method resulted in a more advanced BA estimation on the same film compared with the Fels method [61], while the older TW2 system may significantly underestimate skeletal maturity [62].

There is thus mixed evidence of a secular trend in pubertal development together with an alteration in the onset and also in the tempo of puberty. This secular trend also appears to be present in skeletal maturation. Increased size of contemporary children is only one associated parameter; it is unclear whether there is a direct effect of obesity per se on the advance of puberty and skeletal maturity in the affluent part of the world. Implications of this trend and the readjustment of observed population changes within pathological conditions need further study.

\section{Conclusion}

In part 2 of this review on the use of bone maturation in clinical practice, we have examined the role of BA assessment in modern pediatric management of tall stature, $\mathrm{PP}$ and $\mathrm{CAH}$, and discussed secular trend. While manual bone maturation rating is the main tool used in these conditions, more recent automated techniques may provide advances in this field and facilitate international studies and standardization.

\section{Acknowledgments}

This study is partly indebted to the participants of the International Workgroup on Skeletal Maturity: Kerstin AlbertssonWikland (Sweden), Gary Butler (UK), Janina Caliebe (Germany), Noël Cameron (UK), Oliver Fricke, (Germany), Thomas Hertel 
(Denmark), Ze'ev Hochberg (Israel), Daniela Kiepe, (Germany), David D. Martin (Germany), John Pettifor, (South Africa), Moshe Phillip (Israel), Michael B. Ranke (Germany), Rick R. van Rijn (The Netherlands), Lars Sävendahl (Sweden), Hans Henrik Thodberg (Denmark), George Werther (Australia), Jan M. Wit (The Netherlands) and Angelika Zierl (Germany). The 2009 Meeting of the Workgroup in Tübingen was partly supported by Novo Nordisk.

\section{Disclosure Statement}

Hans Henrik Thodberg is the owner of Visiana, which holds and markets the BoneXpert medical device for automated determination of bone age. The other authors have no conflict of interest.

\section{References}

1 Joss EE, Temperli R, Mullis PE: Adult height in constitutionally tall stature: accuracy of five different height prediction methods. Arch Dis Child 1992;67:1357.

-2 Binder G, Grauer ML, Wehner AV, Wehner F, Ranke MB: Outcome in tall stature. Final height and psychological aspects in $220 \mathrm{pa}-$ tients with and without treatment. Eur J Pediatr 1997;156:905-910.

- 3 Normann EK, Trygstad O, Larsen S, DahlJorgensen K: Height reduction in 539 tall girls treated with three different dosages of ethinyloestradiol. Arch Dis Child 1991;66: 1275.

4 Venn A, Hosmer T, Hosmer D, Bruinsma F, Jones P, Lumley J, Pyett P, Rayner JA, Werther G: Oestrogen treatment for tall stature in girls: estimating the effect on height and the error in height prediction. Clin Endocrinol 2008;68:926.

$\checkmark 5$ De Waal WJ, Greyn-Fokker MH, Stijnen TH, Van Gurp EA, Toolens AM, de Munick Keizer-Schrama S, Aarsen RS, Drop SL: Accuracy of final height prediction and effect of growth-reductive therapy in 362 constitutionally tall children. J Clin Endocrinol Metab 1996;81:1206.

-6 Brämswig JH, Lengerke HJ, Schmidt $\mathrm{H}$, Schellong G: The results of short-term (6 months) high-dose testosterone treatment on bone age and adult height in boys of excessively tall stature. Eur J Pediatr 1988;148: 104-106.

7 Venn A, Bruinsma F, Werther G, Pyett P, Baird D, Jones P, Rayner J, Lumley J: Oestrogen treatment to reduce the adult height of tall girls: long-term effects on fertility. Lancet 2004;364:1513-1518

$\$ 8$ Hendriks AEJ, Laven JSE, Valkenburg O, Fong SL, Fauser BCJM, de Ridder MAJ, de Jong FH, Visser JA, van Ginneken AM, Boot AM, Drop SLS: Fertility and ovarian function in high-dose estrogen-treated tall women. J Clin Endocrinol Metab 2011;96:10981105.

9 Hendriks AEJ, Boellaard WPA, van Casteren NJ, Romijn JC, de Jong FH, Boot AM, Drop SLS: Fatherhood in tall men treated with high-dose sex steroids during adolescence. J Clin Endocrinol Metab 2010;95:5233-5240.
0 Smith EP, Boyd J, Frank GR, Takahashi H, Cohen RM, Specker B, Williams TC, Lubahn DB, Korach KS: Estrogen resistance caused by a mutation in the estrogen-receptor gene in a man. N Engl J Med 1994;331:1056.

11 Reiter EO, Mauras N, McCormick K, Kulshreshtha B, Amrhein J, De Luca F, O'Brien S, Armstrong J, Melezinkova H: Bicalutamide plus anastrozole for the treatment of gonadotropin-independent precocious puberty in boys with testotoxicosis: a phase ii, open-label pilot study (BATT). J Pediatr Endocrinol Metab 2010;23:999-1009.

12 Grandone A, Miraglia del Giudice E, Cirillo G, Santarpia M, Coppola F, Perrone L: Prepubertal gynecomastia in two monozygotic twins with Peutz-Jeghers syndrome: two years' treatment with anastrozole and genetic study. Horm Res Paediatr 2011;75:374-379.

13 Wickman S, Sipilä I, Ankarberg-Lindgren C, Norjavaara E, Dunkel L: A specific aromatase inhibitor and potential increase in adult height in boys with delayed puberty: a randomised controlled trial. Lancet 2001;357: 1743-1748.

14 Hero M, Norjavaara E, Dunkel L: Inhibition of estrogen biosynthesis with a potent aromatase inhibitor increases predicted adult height in boys with idiopathic short stature: a randomized controlled trial. J Clin Endocrinol Metab 2005;90:6396.

15 Salehpour S, Alipour P, Razzaghy-Azar M, Ardeshirpour L, Shamshiri A, Monfared MF, Gharib A: A double-blind, placebo-controlled comparison of letrozole to oxandrolone effects upon growth and puberty of children with constitutional delay of puberty and idiopathic short stature. Horm Res Paediatr 2010;74:428-435.

16 Mauras N, Gonzalez de Pijem L, Hsiang HY, Desrosiers P, Rapaport R, Schwartz ID, Klein KO, Singh RJ, Miyamoto A, Bishop K: Anastrozole increases predicted adult height of short adolescent males treated with growth hormone: a randomized, placebo-controlled, multicenter trial for one to three years. J Clin Endocrinol Metab 2008;93:823.

17 Geffner ME: Aromatase inhibitors to augment height: continued caution and study required. J Clin Res Pediatr Endocrinol 2009; $1: 256$.
8 Dunkel L: Use of aromatase inhibitors to increase final height. Mol Cell Endocrinol 2006;254:207-216.

19 Shulman DI, Francis GL, Palmert MR, Eugster EA: Use of aromatase inhibitors in children and adolescents with disorders of growth and adolescent development. Pediatrics 2008;121:975-983.

20 Diaz-Thomas A, Shulman D: Use of aromatase inhibitors in children and adolescents: what's new? Curr Opin Pediatr 2010;22:501.

-21 Fahmy JL, Kaminsky CK, Kaufman F, Nelson MD, Parisi MT: The radiological approach to precocious puberty. Br J Radiol 2000;73:560.

22 Lazar L, Padoa A, Phillip M: Growth pattern and final height after cessation of gonadotropin-suppressive therapy in girls with central sexual precocity. J Clin Endocrinol Metab 2007;92:3483.

23 Carel JC, Roger M, Ispas S, Tondu F, Lahlou N, Blumberg J, Chaussain JL: Final height after long-term treatment with triptorelin slow release for central precocious puberty: importance of statural growth after interruption of treatment. J Clin Endocrinol Metab 1999;84:1973.

-24 Arrigo T, Cisternino M, Galluzzi F, Bertelloni S, Pasquino AM, Antoniazzi F, Borrelli P, Crisafulli G, Wasniewska M, De Luca F: Analysis of the factors affecting auxological response to GnRH agonist treatment and final height outcome in girls with idiopathic central precocious puberty. Eur J Endocrinol 1999;141:140.

-25 Oostdijk W, Rikken B, Schreuder S, Otten B, Odink R, Rouwe C, Jansen M, Gerver WJ, Waelkens J, Drop S: Final height in central precocious puberty after long term treatment with a slow release GnRH agonist. Arch Dis Child 1996;75:292.

26 Hochberg Z: Endocrine Control of Skeletal Maturation. Basel, Karger, 2002.

27 Vejvoda M, Grant DB: Discordant bone maturation of the hand in children with precocious puberty and congenital adrenal hyperplasia. Acta Paediatr 1981;70:903-905.

28 Martin DD, Stahl K, Schweizer R, Thodberg HH, Ranke MB: Validation of BoneXpert in children with precocious puberty. Horm Res 2008;70(suppl 1):73 
-29 Carel JC, Eugster EA, Rogol A, Ghizzoni L, Palmert MR, on behalf of the members of the ESPE-LWPES GnRH Analogs Consensus Conference Group: Consensus statement on the use of gonadotropin-releasing hormone analogs in children. Pediatrics 2009; 123:e752-e762.

- 30 Bar A, Linder B, Sobel EH, Saenger P, DiMartino-Nardi J: Bayley-Pinneau method of height prediction in girls with central precocious puberty: correlation with adult height. J Pediatr 1995;126:955-958.

- 31 Carel JC, Lahlou N, Roger M, Chaussain JL: Precocious puberty and statural growth. Hum Reprod Update 2004;10:135-147.

-32 Mayer EIE, Homoki J, Ranke MB: Spontaneous growth and bone age development in a patient with 17[alpha]-hydroxylase deficiency: evidence of the role of sexual steroids in prepubertal bone maturation. J Pediatr 1999; 134:371-375.

33 Poznanski AK, Garn SM, Kuhns LR, Sandusky ST: Dysharmonic maturation of the hand in the congenital malformation syndromes. Am J Phys Anthropol 1971;35:417432.

-34 David M, Sempe M, Blanc M, Nicolino M, Forest MG, Morel Y: Final height in 69 patients with congenital adrenal hyperplasia due to 21-hydroxylase deficiency. Arch Pediatr 1994;1:363-367.

35 Ghali I, David M, David L: Linear growth and pubertal development in treated congenital adrenal hyperplasia due to 21-hydroxylase deficiency. Obstet Gynecol Surv 1978;33:120-122.

- 36 Jääskeläinen J, Voutilainen R: Growth of patients with 21-hydroxylase deficiency: an analysis of the factors influencing adult height. Pediatr Res 1997;41:30-33.

-37 Muirhead S, Sellers EAC, Guyda H: Indicators of adult height outcome in classical 21-hydroxylase deficiency congenital adrenal hyperplasia. J Pediatr 2002;141:247-252.

38 Van der Kamp HJ, Otten BJ, Buitenweg N, Muinck Keizer-Schrama S, Oostdijk W, Jansen M, Delemarre-de Waal HA, Vulsma T, Wit JM: Longitudinal analysis of growth and puberty in 21-hydroxylase deficiency patients. Arch Dis Child 2002;87:139-144.
39 Hochberg Z, Schechter J, Benderly A, Leiberman E, Rosler A: Growth and pubertal development in patients with congenital adrenal hyperplasia due to 11-beta-hydroxylase deficiency. Am J Dis Child 1985;139:771-776.

40 Savage MO, Scommegna S, Carroll PV, Ho JTF, Monson JP, Besser GM, Grossman AB: Growth in disorders of adrenal hyperfunction. Horm Res Paediatr 2000;58:39-43.

41 Eugster EA, DiMeglio LA, Wright JC, Freidenberg GR, Seshadri R, Pescovitz OH: Height outcome in congenital adrenal hyperplasia caused by 21-hydroxylase deficiency: a meta-analysis. J Pediatr 2001;138:2632.

42 Bonfig W, Bechtold S, Schmidt H, Knorr D, Schwarz HP: Reduced final height outcome in congenital adrenal hyperplasia under prednisone treatment: deceleration of growth velocity during puberty. J Clin Endocrinol Metab 2007;92:1635-1639.

43 Hargitai G, Solyom J, Battelino T, Lebl J, Pribilincova Z, Hauspie R, Kovacs J, Waldhauser F, Frisch H: Growth patterns and final height in congenital adrenal hyperplasia due to classical 21-hydroxylase deficiency. Horm Res 2000;55:161-171.

44 White PC, Speiser PW: Congenital adrenal hyperplasia due to 21-hydroxylase deficiency. Endocr Rev 2000;21:245-291.

-45 Kant SG, Grote F, De Ru MH, Oostdijk W, Zonderland HM, Breuning MH, Wit JM: Radiographic evaluation of children with growth disorders. Horm Res Paediatr 2007; 68:310-315.

46 Gafni RI, Baron J: Overdiagnosis of osteoporosis in children due to misinterpretation of dual-energy X-ray absorptiometry (DEXA). J Pediatr 2004;144:253-257.

-47 Gordon CM, Bachrach LK, Carpenter TO, Crabtree N, Hajj Fuleihan G, Kutilek S, Lorenc RS, Tosi LL, Ward KA, Ward LM: Dual energy X-ray absorptiometry interpretation and reporting in children and adolescents: the 2007 ISCD Pediatric Official Positions. J Clin Densitom 2008;11:43-58.

48 van Rijn RR, van Kuijk C: Of small bones and big mistakes; bone densitometry in children revisited. Eur J Radiol 2009;71:432-439.

-49 Fricke O, Beccard R, Semler O, Schoenau E: Analyses of muscular mass and function: the impact on bone mineral density and peak muscle mass. Pediatr Nephrol 2010;25:23932400 .
50 Ontell FK, Ivanovic M, Ablin DS, Barlow TW: Bone age in children of diverse ethnicity. Am J Roentgenol 1996;167:1395.

51 Cameron N: The estimation of chronological age in children. Sci Public Policy 1982;9:2027.

-52 Schmeling A, Reisinger W, Geserick G, Olze A: Age estimation of unaccompanied minors. 1. General considerations. Forensic Sci Int 2006; 159:S61-S64.

53 Schmidt S, Koch B, Schulz R, Reisinger W, Schmeling A: Studies in use of the GreulichPyle skeletal age method to assess criminal liability. Leg Med 2008;10:190-195.

54 Ong KK, Ahmed ML, Dunger DB: Lessons from large population studies on timing and tempo of puberty (secular trends and relation to body size): the European trend. Mol Cell Endocrinol 2006;254:8-12.

55 Himes JH: Examining the evidence for recent secular changes in the timing of puberty in US children in light of increases in the prevalence of obesity. Mol Cell Endocrinol 2006;254:13-21.

-56 Aksglaede L, Olsen LW, Sorensen TIA, Juul A: Forty years trends in timing of pubertal growth spurt in 157,000 Danish school children. PLoS One 2008;3:e2728.

57 Aksglaede L, Sorensen K, Petersen JH, Skakkebaek NE, Juul A: Recent decline in age at breast development: the Copenhagen Puberty Study. Pediatrics 2009;123:e932.

58 Lee MM, Sergeyev O, Williams P, Korrick S, Zeilert V, Revich B, Hauser R: Physical growth and sexual maturation of boys in Chapaevsk, Russia. J Pediatr Endocrinol Metab 2003;16:169.

-59 Ashizawa K, Kumakura C, Zhou X, Jin F, Cao J: RUS skeletal maturity of children in Beijing. Ann Hum Biol 2005;32:316-325.

60 Freitas D, Maia J, Beunen G, Lefevre J, Claessens A, Marques A, Rodrigues A, Silva C, Crespo M, Thomis M: Skeletal maturity and socio-economic status in Portuguese children and youths: the Madeira growth study. Ann Hum Biol 2004;31:408-420.

61 Malina RM, Chamorro M, Serratosa L, Morate F: TW3 and Fels skeletal ages in elite youth soccer players. Ann Hum Biol 2007;34: 265-272.

62 Ahmed ML, Warner JT: TW2 and TW3 bone ages: time to change? Br Med J 2007;92:371. 